\title{
A General Matrix Model Of Support Department Cost Allocation Methods
}

\author{
Denton Collins, (Email: dlcollins@uh.edu), University of Houston
}

\begin{abstract}
This paper demonstrates that the direct and step methods for making support department allocations are really special cases of the more general reciprocal method, and that the different allocations can be estimated using the same basic model. Simple modification of the matrix of resource consumption between support departments is all that is required to use a matrix algebra approach for all three methods. Potential benefits accruing to users and practitioners from the use of these models and areas of possible future research are discussed in the paper.
\end{abstract}

\section{Introduction}

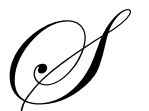

upport departments and their costs have been increasingly important over the last decade as organizations have been consolidating more business functions in subunits that exist primarily to provide services to other subunits (Forst 1997). Reflecting the need to build performance measurement systems to accurately assess the efficiency and effectiveness of these shared services, this paper develops matrix models for the direct and step methods of support department cost allocation and contrasts these models with the matrix model of the reciprocal method. Each of these allocation methods explicitly allocate the costs of support departments to the operating departments that consume those services. Consistent with prior research, a "support department" (or "service department") is defined in this paper as any stand-alone department or business unit that is not directly involved in generating output. For example, technology support, administrative support, and legal support would all fall under the traditional definition of "support departments." Cost systems often require these costs to be allocated to operating departments in order to assign overhead costs to products and services and to facilitate decision making involving the shared support services.

In addition to providing services to operating departments, these support departments also provide services to other service departments. The three methods of cost allocation (direct, step and reciprocal methods) differ from each other in the extent to which inter-support department activities are recognized in computing allocated costs. The direct method does not consider any of the interactions between support departments, while the reciprocal method fully incorporates these interactions. The step method considers only some of these interactions. When there are no interactions between support departments, the three methods yield identical allocations (Maher 1997).

Kaplan (1973, p. 738) shows that the reciprocal method is to be preferred over the other methods because only it "yields allocations that are consistent with the opportunity costs of providing output from service departments." However, the reciprocal method has not been widely adopted by organizations, in part because the allocations are computed by solving a system of simultaneous equations, which leads to the perception that the method is too complex and difficult to understand (Horngren, Foster and Datar 1997, Garrison and Noreen 2000). Even though the availability of easy to use spreadsheet software makes it easy to implement the reciprocal method using a matrix algebra approach, widespread adoption has not been achieved (Garrison and Noreen 2000).

While the matrix model of the reciprocal method has been exhaustively developed in the prior literature (see, e.g, Kaplan 1973), the direct and step methods are typically presented as more ad hoc approaches whose primary advantage is purported to be reduced complexity. This reduced complexity is typically illustrated in

Readers with comments or questions are encouraged to contact the author via email. 
textbooks and professional guidance under simplified scenarios involving a small number of support departments $(\leq 3)$ providing services to a small number of operating departments $(\square \leq 3)$. Consistent with these relatively simple settings, the computations associated with the direct and step methods are typically presented as a set of simple iterative calculations, and these computations involving a small number of departments are, in fact, relatively less complex than the reciprocal method and usually easier to understand. For example, Burch (1994), Horngren, Foster and Datar (1997) and Maher (1997) all use table approaches in computing direct and step method allocations involving anywhere from two to four support departments; however, all three use a simultaneous equations approach in computing reciprocal method allocations. However, as the number of support departments and number of operating departments increases, the relative complexity advantage of both of the simpler methods decreases. In real world settings involving many support departments and many operating departments, the step and direct method calculations can become quite cumbersome and also will often require custom-designed, setting-specific spreadsheet applications to implement. ${ }^{1}$

This paper demonstrates that the direct and step approaches are really special cases of the more general reciprocal approach. Defining these three methods of allocation as variants of a general model is important for at least three reasons. First, as suggested above, spreadsheet software with powerful matrix manipulation functions makes it easier to implement algebraic solutions to cost allocation problems. The lack of a general model for step and direct methods suggests that relatively complicated support department/operating department settings will require similarly complicated, setting-specific spreadsheet applications in order to compute these allocations. The availability of a general model for all three methods that can be easily implemented on a spreadsheet using built-in matrix manipulation functions should make it easier for managers to perform "what-if" and cost-benefit analyses in the choice of accounting methods and in cost management decisions. ${ }^{2}$ Second, under those circumstances when firms continue to use either the direct or step methods and the settings being analyzed involve many support departments and many operating departments, a general model using a matrix algebra solution should ease the computational burden on practitioners. Finally, the general approach highlights the differences between the methods and should make these differences more understandable for both business students and managers. As a result, practitioners may be motivated to move toward the theoretically more defensible reciprocal method.

\section{The Setting}

Assume that there are $n$ support departments, denoted by $\mathrm{S}_{1}, \mathrm{~S}_{2}, \ldots, \mathrm{S}_{\mathrm{n}}$, and $m$ operating departments, denoted by $\mathrm{P}_{1}, \mathrm{P}_{2}, \ldots, \mathrm{P}_{\mathrm{m}}$. The support departments incur direct variable costs of $\mathrm{C}_{1}, \mathrm{C}_{2}, \ldots, \mathrm{C}_{\mathrm{n}}$, respectively. Further, assume that $\mathrm{S}_{1}$ provides its services to itself and to the other $n-1$ support departments in proportions denoted by $\lambda_{\mathrm{il}}$, where $i$ denotes the department to which $\mathrm{S}_{1}$ supplies its services, $\mathrm{S}_{2}$ provides its services to itself and to the other support departments in proportions denoted by $\lambda_{\mathrm{i} 2}$, and so forth. Assume as well that $\mathrm{S}_{1}$ provides its services to the $m$ operating departments in proportions denoted by $\omega_{1 \mathrm{i}}$, where $i$ denotes the operating department to which $\mathrm{S}_{1}$ supplies its services, $S_{2}$ provides its services to the $m$ operating departments in proportions denoted by $\omega_{2 \mathrm{i}}$, and so forth. Note that $\Sigma \lambda_{\mathrm{i}=1}$ to $, \mathrm{j}, \Sigma \omega_{\mathrm{j}, \mathrm{i}=1 \text { to } \mathrm{m}}=1$ for each service department $j$ under this general specification.

\section{Reciprocal Method Allocations}

With the reciprocal method (as with the other methods of allocation service department costs), the objective is to allocate all of the service departments' costs to the various operating departments. However, in contrast to the other methods, the reciprocal method fully models the interactions between support departments using a system of linear simultaneous equations. Solving this system of equations yields the reciprocated costs that are subsequently allocated to the other support departments and to the operating departments (see, e.g., Kaplan 1973, Kaplan and Atkinson 1998). These reciprocated costs include not only the direct costs of the support department but also the costs allocated to it from the other support departments. Kaplan (1973) and a number of others (see, e.g., Churchill 1964, Manes 1965) have worked out the mathematics of the more general reciprocal method solution using matrix algebra by showing that the method can be modeled as a form of a Leontief input-output economic model. The general model for the complete reciprocated costs can be stated as follows (Kaplan and Atkinson 1998):

$$
\left(\boldsymbol{I}-\boldsymbol{A}^{\mathrm{R}}\right) \boldsymbol{b}^{\mathrm{R}}=\boldsymbol{c}
$$


where $\boldsymbol{I}$ is an $n \times n$ identity matrix, $\boldsymbol{A}^{\mathrm{R}}$ is the $n \times n$ matrix of proportions of services provided by each support department to itself and to each of the other support departments, $\boldsymbol{b}^{\mathrm{R}}$ is an $n \times 1$ vector of complete reciprocated costs (i.e., the costs after all allocations of costs to and from itself and other support departments) for each support department, and $\boldsymbol{c}$ is the $n \times 1$ vector of direct costs initially traced to each of the $n$ support departments (consisting of elements $c_{1}, \ldots, c_{\mathrm{n}}$ ). The element in the $i$ th row and $j$ th column of the matrix $\boldsymbol{A}^{\mathrm{R}}$ represents the proportion of the total output of support department $j$ consumed by support department $i$. The matrix $\boldsymbol{A}^{\mathrm{R}}$ therefore takes on the form:

$$
\boldsymbol{A}^{\mathrm{R}}=\left\lceil\begin{array}{cccccc}
\lambda_{11} & \lambda_{12} & \lambda_{13} & \ldots \ldots & \lambda_{1 \mathrm{n}} \\
\lambda_{21} & \lambda_{22} & \lambda_{23} & \ldots \ldots & \ldots & \lambda_{2 \mathrm{n}} \\
\cdot & \cdot & \cdot & \ldots \ldots & . \\
\cdot & \cdot & \cdot & \ldots \ldots & \ldots & \cdot \\
\lambda_{\mathrm{n} 1} & \lambda_{\mathrm{n} 2} & \lambda_{\mathrm{n} 3} & \ldots \ldots & \lambda_{\mathrm{nn}}
\end{array}\right]
$$

Note that, when $i=j, \lambda_{\mathrm{ij}}$ measures each support department's proportional consumption of its own services. ${ }^{3}$ The solution for the complete reciprocated costs (i.e., the vector $\boldsymbol{b}^{\mathrm{R}}$ ) is then given by:

$$
\left(\boldsymbol{I}-\boldsymbol{A}^{\mathrm{R}}\right)^{-1} \boldsymbol{c}=\boldsymbol{b}^{\mathrm{R}}
$$

As Kaplan (1973) demonstrates, the elements of the vector $\boldsymbol{b}^{\mathrm{R}}$ reflect the "true" total costs of the $n$ support departments. From these reciprocated costs, the firm can also compute the effective unit cost of providing the services of a given support department. These reciprocated costs are therefore important if the firm wishes to evaluate the unit costs of providing internal services relative to the external purchase of services.

To compute the cost allocation to a given operating department, the complete reciprocated cost of each support department is multiplied by the respective proportion of services provided to that department, as follows:

Support Department $j$ costs to be allocated to Operating Department $1=\mathrm{b}^{\mathrm{R}}{ }_{\mathrm{j}} \omega_{\mathrm{j} 1}$ Support Department $j$ costs to be allocated to Operating Department $2=\mathrm{b}^{\mathrm{R}}{ }_{\mathrm{j}} \omega_{\mathrm{j} 2}$

Support Department $j$ costs to be allocated to Operating Department $\dot{m}=\dot{\mathrm{b}}_{\mathrm{j}}^{\mathrm{R}} \omega_{\mathrm{jm}}$

where $\mathrm{b}^{\mathrm{R}}{ }_{\mathrm{j}}$ is the element of the $n \times 1$ vector $\boldsymbol{b}^{\mathrm{R}}$ that represents the complete reciprocated cost of support department $j$ computed previously. Consistent with Kaplan and Atkinson (1998, 81), this final allocation can be accomplished by multiplying the transpose of $\boldsymbol{b}^{\mathrm{R}}$ by the required consumption matrix. The $n \times m$ consumption matrix, $\boldsymbol{W}$, contains elements $\omega_{\mathrm{ji}}$ such that the element in the $j$ th row and the $i$ th column represents the proportion of support department $j$ 's total output that is consumed by operating department $i$. The final allocation is thus computed by:

$$
b^{\mathrm{R}}, \boldsymbol{W}=\boldsymbol{x}^{\mathrm{R}}
$$

where $x^{\mathrm{R}}$ is the $1 \mathrm{x} m$ vector of allocations to operating departments 1 through $m$ computed using the reciprocal method, and the operator " " " indicates the transpose of the vector $\boldsymbol{b}^{\mathrm{R}}$.

\section{Direct Method Allocations}

Under the direct method, a support department's costs are allocated to a particular operating department based on that operating department's demand for support, relative to the overall level of support provided to all operating departments. However, only the direct costs of the support departments (i.e., the elements of the vector $\boldsymbol{c}$ ) are allocated to operating departments, and these allocations are based proportionately on only the demands (i.e., the $\left.\omega_{\mathrm{ji}}\right)$ of the operating departments; no support department costs are allocated to other support departments. This requires adjusting the proportionate demands of the operating departments to reflect the unallocated inter-support department service consumption. To illustrate, allocation of the direct costs of Support Department $i$ would proceed as follows: 
Support Department $j$ costs to be allocated to Operating Department $1=c_{\mathrm{j}}\left[\omega_{\mathrm{j} 1} /\left(\omega_{\mathrm{j} 1}+\omega_{\mathrm{j} 2}+\ldots+\omega_{\mathrm{jm}}\right)\right]$ Support Department $j$ costs to be allocated to Operating Department $2=c_{\mathrm{j}}\left[\omega_{\mathrm{j} 2} /\left(\omega_{\mathrm{j} 1}+\omega_{\mathrm{j} 2}+\ldots+\omega_{\mathrm{jm}}\right)\right]$

Support Department $j$ costs to be allocated to Operating Department $m=c_{\mathrm{j}}\left[\omega_{\mathrm{jm}} /\left(\omega_{\mathrm{j} 1}+\omega_{\mathrm{j} 2}+\ldots+\omega_{\mathrm{jm}}\right)\right]$

Note that $\left(\omega_{\mathrm{j} 1}+\omega_{\mathrm{j} 2}+\ldots+\omega_{\mathrm{jm}}\right)=\Sigma \omega_{\mathrm{j}, \mathrm{i}=1 \text { to } \mathrm{m}}$, which is the overall proportion of services provided by Support De-

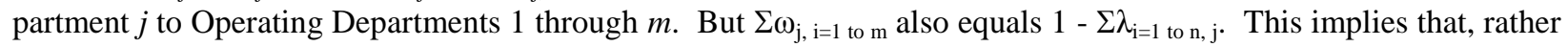
than adjust the demands of the operating departments for Support Department $i$ 's services, a more convenient approach would be to adjust the costs of Support Department $i$ as follows:

Support Department $j$ costs to be allocated to Operating Dept. $1=c_{\mathrm{j}}\left[\omega_{\mathrm{j} 1} /\left(1-\Sigma \lambda_{\mathrm{ij}}\right)\right]=\left[c_{\mathrm{j}} /\left(1-\Sigma \lambda_{\mathrm{ij}}\right)\right] \omega_{\mathrm{j} 1}$ Support Department $j$ costs to be allocated to Operating Dept. $2=c_{\mathrm{j}}\left[\omega_{\mathrm{j} 2} /\left(1-\Sigma \lambda_{\mathrm{ij}}\right)\right]=\left[c_{\mathrm{j}} /\left(1-\Sigma \lambda_{\mathrm{ij}}\right)\right] \omega_{\mathrm{j} 2}$

Support Department $j$ costs to be allocated to Operating Dept. $m=\dot{c}_{\mathrm{j}}\left[\omega_{\mathrm{jm}} /\left(1-\Sigma \lambda_{\mathrm{ij}}\right)\right]=\left[c_{\mathrm{j}} /\left(1-\Sigma \lambda_{\mathrm{ij}}\right)\right] \omega_{\mathrm{jm}}$

This restated cost term $\left[c_{\mathrm{j}} /\left(1-\Sigma \lambda_{\mathrm{ij}}\right)\right]$ now represents the cost of Support Department $j$, adjusted for the consumption of resources by other support departments (including itself). These restated or adjusted costs are now somewhat analogous to the elements of the vector of reciprocated costs (i.e., the vector $\boldsymbol{b}^{\mathrm{R}}$ ) that characterize the reciprocal method. The implication is that a matrix algebra approach can be implemented to solve this direct method allocation problem as well.

The modification of the Kaplan and Atkinson's (1998) reciprocal method model to compute the direct method allocations is straightforward, and requires only a re-specification of the resource consumption matrix $\boldsymbol{A}$ as follows:

$$
\left(\boldsymbol{I}-\boldsymbol{A}^{\mathrm{D}}\right) \boldsymbol{b}^{\mathrm{D}}=\boldsymbol{c}
$$

where $\boldsymbol{I}$ is an $n \times n$ identity matrix, $\boldsymbol{A}^{\mathrm{D}}$ is the modified $n \times n$ diagonal matrix of cumulative proportions of services provided by each support department, $\boldsymbol{b}^{\mathrm{D}}$ is an $n \times 1$ vector of adjusted costs for each support department that will be allocated to the operating departments, and $c$ is the $n \times 1$ vector of direct costs initially traced to the support departments. In contrast to the reciprocal method, the jth diagonal element of matrix $A^{\mathrm{D}}$ consists of $\Sigma \lambda_{\mathrm{i}=1}$ to n, j, which represents the sum of the proportions of Support Department $j$ 's services provided to support departments 1 through $n$. The off-diagonal elements of this matrix are all zeros. ${ }^{4}$ The net effect of this specification is that there is no explicit consideration of the interdependencies between support departments. The matrix $\boldsymbol{A}^{\mathrm{D}}$ therefore takes on the form:

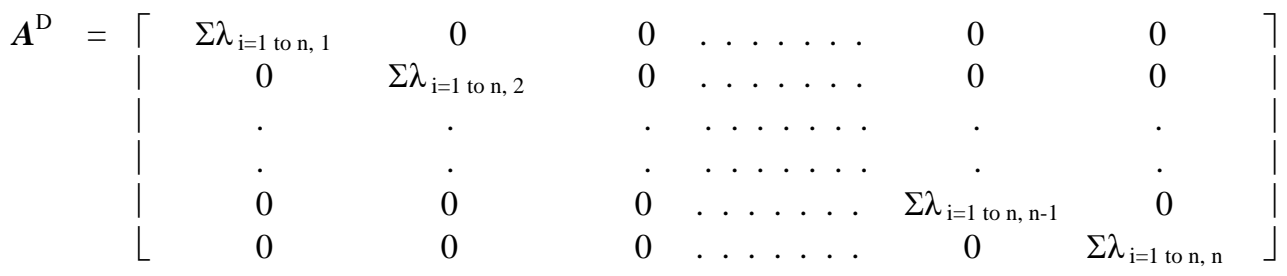

Then the solution for the adjusted costs under the direct method can be stated as:

$$
\left(\boldsymbol{I}-\boldsymbol{A}^{\mathrm{D}}\right)^{-1} \boldsymbol{c}=\boldsymbol{b}^{\mathrm{D}}
$$

The rationale behind this modification of $\boldsymbol{A}$ is similarly straightforward. A diagonal element in $\boldsymbol{A}^{\mathrm{D}}$, say

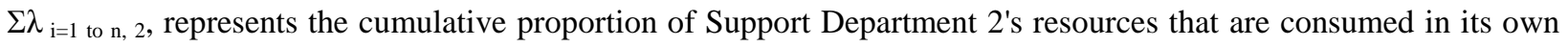
operations and by the other support departments. However, the direct method effectively treats this cumulative pro- 
portion as if it reflects self-consumption of services. The mathematics are straight forward as well. The diagonal elements of $\left(\boldsymbol{I}-\boldsymbol{A}^{\mathrm{D}}\right)$ then are $\left(1-\Sigma \lambda_{\mathrm{ij}}\right)$, and the diagonal elements of $\left(\boldsymbol{I}-\boldsymbol{A}^{\mathrm{D}}\right)^{-1}$ are $1 /\left(1-\Sigma \lambda_{\mathrm{ij}}\right)$. When the matrix ( $\left.\boldsymbol{I}-\boldsymbol{A}^{\mathrm{D}}\right)^{-1}$ is multiplied by the respective terms in $\boldsymbol{c}$, the adjusted costs for the allocations to the operating departments are obtained (as similarly computed above). For example, $c_{2}\left[1 /\left(1-\Sigma \lambda_{\mathrm{i}=1 \text { to n, } 2)}\right]=b_{2}{ }^{\mathrm{D}}\right.$ represents the adjusted cost of Support Department 2 that, when multiplied by $\omega_{2 i}$, yields the allocation to the operating department $i$. Further, the off-diagonal elements are all zero, insuring that none of Support Department 2's costs are allocated to the other support departments. Hence, the direct method adjusts the direct costs of a support department to reflect that some of these resources are consumed by the support departments and therefore are not available for consumption by the operating departments. At the same time, the approach inhibits the allocation of these costs to other support departments. In effect, the direct method allocates costs to the operating departments as if these departments were consuming all of these services.

As with the reciprocal method, the final allocation of costs to the operating departments can be accomplished by multiplying the $n \times 1$ vector of adjusted costs, $\boldsymbol{b}^{\mathrm{D}}$, by the required $n \times m$ consumption matrix of proportions, $\boldsymbol{W}$, which was previously defined. This final allocation is computed by:

$$
\boldsymbol{b}^{\mathrm{D}} \boldsymbol{W}=\boldsymbol{x}^{\mathrm{D}}
$$

where $\boldsymbol{x}^{\mathrm{D}}$ is the $1 \times \mathrm{x} m$ vector of allocations to operating departments 1 through $m$. Note that, because support department costs are not allocated back to other support departments through the recognition of the reciprocal services, operating departments are allocated costs in amounts that do not accurately reflect their proportional consumption of those support resources.

\section{The Step Method}

As noted previously, the step method incorporates some, but not all, of the interactions between support departments. Its use is advocated by practitioners as an alternative to the reciprocal and direct methods because allocations using the step method often approximate those produced by the reciprocal method, but without the perceived complexity inherent in solving a system of simultaneous equations (Horngren, Foster and Datar 1997). ${ }^{5}$ The method requires the firm to choose (usually arbitrarily) the sequence in which support department costs are to be allocated to other support departments. ${ }^{6}$ In the initial step, the direct costs of the first selected support department are allocated to the remaining support departments and to the operating departments based on their relative consumption of services. Self-service consumption is ignored in the allocations, which requires adjusting the proportionate demands of the other support departments and the operating departments to reflect this exclusion. The next step sums the direct costs of the second support department with the costs allocated to it from the first support department, and then allocates this cumulative total to the remaining support departments and to the operating departments. This process continues until all support department costs have been allocated. At no stage of this process are any support department costs allocated back to any support department whose costs have already been allocated. Obviously, every additional support department adds another set of calculations and adds to the degree of complexity.

This sequential process can be developed more rigorously in the following manner. Assume that the step allocations occur in numerical order. The first step allocates Support Department 1's direct costs $\left(c_{1}\right)$ to the other $n$ - 1 support departments and to the $m$ operating departments based on their adjusted proportionate demand for support resources. Taking into account Support Department 1's self-consumption, the allocation of costs to the remaining $n-1$ support departments and to the $m$ operating departments proceeds as follows:

$$
\begin{aligned}
& \text { Support Department } 1 \text { costs allocated to Support Department } 2 \\
& =c_{1}\left[\lambda_{21} /\left(\lambda_{21}+\ldots+\lambda_{\mathrm{n} 1}+\omega_{11}+\ldots+\omega_{1 \mathrm{~m}}\right)\right] \\
& \text { Support Department } 1 \text { costs allocated to Support Department } n \\
& \text { Support Department } 1 \text { costs allocated to Operating Department } 1 \\
& =c_{1}\left[\lambda_{\mathrm{n} 1} /\left(\lambda_{21}+\ldots+\lambda_{\mathrm{n} 1}+\omega_{11}+\ldots+\omega_{1 \mathrm{~m}}\right)\right] \\
& =c_{1}\left[\omega_{11} /\left(\lambda_{21}+\ldots+\lambda_{\mathrm{n} 1}+\omega_{11}+\ldots+\omega_{1 \mathrm{~m}}\right)\right] \\
& \text { Support Department } 1 \text { costs allocated to Operating Department } \dot{m} \\
& =c_{1}\left[\omega_{1 \mathrm{~m}} /\left(\lambda_{21}+\ldots+\lambda_{\mathrm{n} 1}+\omega_{11}+\ldots+\omega_{1 \mathrm{~m}}\right)\right]
\end{aligned}
$$

Note that $\left[\left(\lambda_{21}+\ldots+\lambda_{n 1}\right)+\left(\omega_{11}+\ldots+\omega_{1 \mathrm{~m}}\right)\right]=1-\lambda_{11}$, where $\lambda_{11}$ represents the proportion of services con- 
sumed by Support Department 1 in its own operations. As with the direct method, rather than adjust the demands of the operating departments for Support Department 1's self-consumption, a more convenient approach might be to adjust or restate the costs of Support Department 1 to be allocated as follows:

$$
\begin{aligned}
& \text { Support Department } 1 \text { costs allocated to Support Department } 2=c_{1}\left[\lambda_{21} /\left(1-\lambda_{11}\right)\right]=\left[c_{1} /\left(1-\lambda_{11}\right)\right] \lambda_{21} \\
& \text { Support Department } 1 \text { costs allocated to Support Department } n=c_{1}\left[\lambda_{\mathrm{n} 1} /\left(1-\lambda_{11}\right)\right]=\left[c_{1} /\left(1-\lambda_{11}\right)\right] \lambda_{\mathrm{n} 1} \\
& \text { Support Department } 1 \text { costs allocated to Operating Department } 1=c_{1}\left[\omega_{11} /\left(1-\lambda_{11}\right)\right]=\left[c_{1} /\left(1-\lambda_{11}\right)\right] \omega_{11} \\
& \text { Support Department } 1 \text { costs allocated to Operating Department } m=c_{1}\left[\omega_{1 \mathrm{~m}} /\left(1-\lambda_{11}\right)\right]=\left[c_{1} /\left(1-\lambda_{11}\right)\right] \omega_{1 \mathrm{~m}}
\end{aligned}
$$

Thus, similar to the direct method, $\left[c_{1} /\left(1-\lambda_{11}\right)\right]$ represents the cost of Support Department 1 , as adjusted for self-consumption of resources, that will be allocated to the remaining support departments and the operating departments.

The second step requires allocation of the second support department's direct costs plus those costs allocated to it from the first support department. The total of these two components is $c_{2}+\lambda_{21}\left[c_{1} /\left(1-\lambda_{11}\right)\right]$. Note that none of Support Department 2's costs will be allocated back to Support Department 1 and that, similar to the first step, adjustment for Support Department 2's consumption of its own services is required. This second-step allocation of the total costs of Support Department 2 (designated $S_{2}$ ) to the remaining support departments (designated $\mathrm{S}_{3}$ through $\mathrm{S}_{\mathrm{n}}$ ) and the operating departments (designated $\mathrm{P}_{1}$ through $\mathrm{P}_{\mathrm{m}}$ ) is accomplished as follows:

$$
\begin{aligned}
& \mathrm{S}_{2}=>\mathrm{S}_{3}=\left\{c_{2}+\lambda_{21}\left[c_{1} /\left(1-\lambda_{11}\right)\right]\right\}\left[\lambda_{32} /\left(\lambda_{32}+\ldots+\lambda_{\mathrm{n} 2}+\omega_{21}+\ldots+\omega_{2 \mathrm{~m}}\right)\right] \\
& \dot{\mathrm{S}}_{2} \Rightarrow \dot{\mathrm{S}}_{\mathrm{n}} \quad=\left\{\dot{c}_{2}+\lambda_{21}\left[c_{1} /\left(1-\lambda_{11}\right)\right]\right\}\left[\lambda_{\mathrm{n} 2} /\left(\lambda_{32}+\ldots+\lambda_{\mathrm{n} 2}+\omega_{21}+\ldots+\omega_{2 \mathrm{~m}}\right)\right] \\
& \mathrm{S}_{2}=>\mathrm{P}_{1}=\left\{c_{2}+\lambda_{21}\left[c_{1} /\left(1-\lambda_{11}\right)\right]\right\}\left[\lambda_{21} /\left(\lambda_{32}+\ldots+\lambda_{\mathrm{n} 2}+\omega_{21}+\ldots+\omega_{2 \mathrm{~m}}\right)\right] \\
& \dot{\mathrm{S}}_{2} \Rightarrow \dot{\mathrm{P}}_{\mathrm{m}}=\left\{c_{2}+\lambda_{21}\left[c_{1} /\left(1-\lambda_{11}\right)\right]\right\}\left[\lambda_{2 \mathrm{~m}} /\left(\lambda_{32}+\ldots+\lambda_{\mathrm{n} 2}+\omega_{21}+\ldots+\omega_{2 \mathrm{~m}}\right)\right]
\end{aligned}
$$

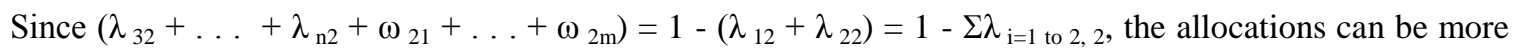
conveniently stated as follows:

$$
\begin{aligned}
& \mathrm{S}_{2}=>\mathrm{S}_{3}=\left\{c_{2}+\lambda_{21}\left[c_{1} /\left(1-\lambda_{11}\right)\right]\right\}\left\{\lambda_{32} /\left[1-\left(\lambda_{12}+\lambda_{22}\right)\right]\right\}=\left\{\left[c_{2}+\lambda_{21}\left[c_{1} /\left(1-\lambda_{11}\right)\right]\right] /\left[1-\left(\lambda_{12}+\lambda_{22}\right)\right]\right\} \lambda_{32} \\
& \left.\dot{\mathrm{S}_{2}} \Rightarrow \dot{\mathrm{S}}_{\mathrm{n}}=\left\{c_{2}+\lambda_{21}\left[c_{1} /\left(1-\lambda_{11}\right)\right]\right\}\left\{\lambda_{\mathrm{n} 2} / \dot{1}-\left(\lambda_{12}+\dot{\lambda}_{22}\right)\right]\right\} \quad=\left\{\left[\mathrm{c}_{2}+\lambda_{21}\left[\mathrm{c}_{1} /\left(1-\lambda_{11}\right)\right]\right] /\left[1-\left(\lambda_{12}+\lambda_{22}\right)\right]\right\} \lambda_{\mathrm{n} 2} \\
& \mathrm{~S}_{2} \Rightarrow \mathrm{P}_{1}=\left\{c_{2}+\lambda_{21}\left[c_{1} /\left(1-\lambda_{11}\right)\right]\right\}\left\{\omega_{21} /\left[1-\left(\lambda_{12}+\lambda_{22}\right)\right]\right\}=\left\{\left[\mathrm{c}_{2}+\lambda_{21}\left[\mathrm{c}_{1} /\left(1-\lambda_{11}\right)\right]\right] /\left[1-\left(\lambda_{12}+\lambda_{22}\right)\right]\right\} \omega_{21}
\end{aligned}
$$

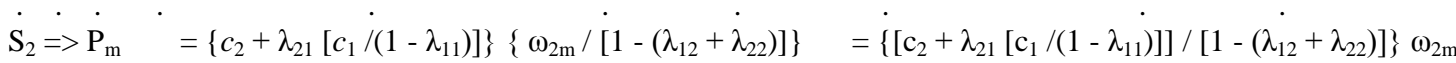

The adjusted or restated cost of Support Department 2 that will be allocated from Support Department 2 to the remaining $n-2$ support departments and the operating departments can thus be expressed as:

$$
\left\{c_{2}+\lambda_{21}\left[c_{1} /\left(1-\lambda_{11}\right)\right]\right\} /\left[1-\left(\lambda_{12}+\lambda_{22}\right)\right]
$$

The third stage allocates the adjusted or restated costs of Support Department 3 to the remaining $n$ - 3 support departments and to the operating departments. The total costs to be allocated (prior to adjustment) would consist of Support Department 3's direct costs $\left(\mathrm{C}_{3}\right)$, plus the costs allocated to Support Department 3 from Support Department 1 (represented by $\lambda_{31}\left[C_{1} /\left(1-\lambda_{11}\right)\right]$ as derived in the first stage) and from Support Department 2 (represented by $\lambda_{32}\left\{\left[\mathrm{C}_{2}+\lambda_{21}\left[\mathrm{C}_{1} /\left(1-\lambda_{11}\right)\right]\right] /\left[1-\left(\lambda_{12}+\lambda_{22}\right)\right]\right\}$ as derived in the second stage). This total cost amount would then be adjusted for Support Department 3's consumption of its own services and for the fact that no costs are allocated back to the first and second support departments. Following the same iterative process developed above (and foregoing some intermediate steps), these adjusted costs would be:

$$
\left\{\mathrm{C}_{3}+\lambda_{31}\left[\mathrm{C}_{1} /\left(1-\lambda_{11}\right)\right]+\lambda_{32}\left\{\left[\mathrm{C}_{2}+\lambda_{21}\left[\mathrm{C}_{1} /\left(1-\lambda_{11}\right)\right]\right] /\left[1-\left(\lambda_{12}+\lambda_{22}\right)\right]\right\}\right\} /\left[1-\left(\lambda_{13}+\lambda_{32}+\lambda_{33}\right)\right]
$$

and the step process would begin again with these adjusted costs allocated to the remaining $n$ - 3 support depart- 
ments and to the operating departments. The sequence would end when all of the $n$ support departments' costs have been allocated to operating departments.

Clearly, this iterative process increases in complexity dramatically as the number of support department increases. Implementing this system on a spreadsheet requires the development of a setting-specific application and can become quite cumbersome as the $n$ support departments gets large, with every additional support department adding another set of calculations. This suggests that development of a general model might mitigate the application development burden.

The step form of the general model can be developed as follows. Note that the adjusted costs as developed above [e.g., the terms $\left[\mathrm{C}_{1} /\left(1-\lambda_{11}\right)\right]$ and $\left.\left.\left\{\mathrm{C}_{2}+\lambda_{21}\left[\mathrm{C}_{1} /\left(1-\lambda_{11}\right)\right]\right\} /\left[1-\left(\lambda_{12}+\lambda_{22}\right)\right]\right)\right]$ are conceptually similar to the complete reciprocated costs that characterize the reciprocal method. As with the direct method, a more convenient matrix algebra approach can be developed to solve this step method allocation problem as well. Similar to the other two methods, the general form of the step model can be stated in the following manner:

$$
\left(\boldsymbol{I}-\boldsymbol{A}^{\mathrm{S}}\right) \boldsymbol{b}^{\mathrm{S}}=\boldsymbol{c}
$$

where $\boldsymbol{I}$ is an $n \times n$ identity matrix, $\boldsymbol{A}^{\mathrm{S}}$ is the $n \times n$ resource consumption matrix of service proportions, $\boldsymbol{b}^{\mathrm{S}}$ is an $n \times 1$ vector of adjusted allocable costs for each support department, and $\boldsymbol{c}$ is the $n \times 1$ vector of direct costs initially traced to each of the $n$ support departments. However, the composition of the $\boldsymbol{A}^{\mathrm{S}}$ resource consumption matrix differs from that of either the reciprocal and direct method counterparts. Not surprisingly, the re-specification of the matrix represents a combination of the two approaches. Specifically, the step method is similar to the direct method in that no support department is allocated any of its own direct costs, and one or more support departments' costs will not be allocated back to other support departments whose costs have already been allocated. It is similar to the reciprocal method in that some support department costs are allocated to other support departments. The matrix $\boldsymbol{A}^{\mathrm{S}}$ therefore takes on the form:

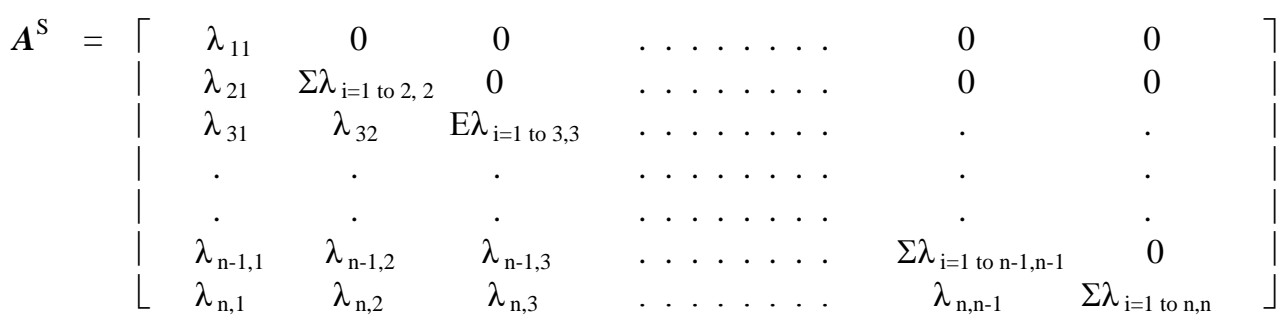

It is important to note that the vector $\boldsymbol{c}$ and the columns of $\boldsymbol{A}^{\mathrm{S}}$ must reflect the sequence in which the step process allocations occur, with the first column made up of the $\lambda_{\mathrm{il}}$ of the first support department whose costs are to be allocated first, the second column made up of the $\lambda_{\mathrm{i} 2}$ of the second support department, and so forth. Consistent with Kaplan and Atkinson (1998), the solution for the adjusted costs to be allocated to the operating departments under the step method (i.e., the vector $\boldsymbol{b}^{\mathrm{S}}$ ) is then given by:

$$
\left(\boldsymbol{I}-\boldsymbol{A}^{\mathrm{S}}\right)^{-1} \boldsymbol{c}=\boldsymbol{b}^{\mathrm{S}}
$$

Note that the first element in the vector $\boldsymbol{b}^{\mathrm{S}}$ represents the adjusted costs of the support department whose costs are allocated first, the second element represents the adjusted costs of the second allocated support department, and so on. As with the reciprocal and direct methods, the final allocation of costs to the operating departments can be accomplished by multiplying the transpose of the $n \times 1$ vector of adjusted costs, $\boldsymbol{b}^{\mathrm{S}}$, by the required $n \times m$ consumption matrix of proportions, $\boldsymbol{W}$, which was previously defined. This final allocation is computed by:

$$
\boldsymbol{b}^{\mathrm{S},} \boldsymbol{W}=\boldsymbol{x}^{\mathrm{S}}
$$


where $\boldsymbol{x}^{\mathrm{S}}$ is the $1 \times m$ vector of allocations to operating departments 1 through $m$. Similar to the order condition imposed on $\boldsymbol{A}^{\mathrm{S}}$, the first row of the matrix $\boldsymbol{W}$ must reflect the $\omega_{1 \mathrm{i}}$ of the support department whose costs were allocated first, the second row must reflect the $\omega_{2 \mathrm{i}}$ of the support department whose costs were allocated second, and so forth.

Note that the elements of $\boldsymbol{A}^{\mathrm{S}}$ above the diagonal are identical to the corresponding elements in $\boldsymbol{A}^{\mathrm{D}}$, while the elements of $\boldsymbol{A}^{\mathrm{S}}$ below the diagonal are identical to the corresponding elements in $\boldsymbol{A}^{\mathrm{R}}$. ${ }^{7}$ But the composition of the diagonal elements of $\boldsymbol{A}^{\mathrm{S}}$ requires a bit of clarification. The first diagonal term is simply $\lambda_{11}$, representing Department 1's consumption of its own services. The second diagonal term, $\Sigma \lambda_{j=1}$ to 2,2 represents the sum of $\lambda_{12}$ and $\lambda_{22}$, or the proportion of Department 2's services consumed by Departments 1 and 2; however, these proportions are treated as if they were consumed only by Department 2 . The third diagonal term, $\Sigma \lambda_{\mathrm{j}=1}$ to 3,3 represents the sum of $\lambda_{13}, \lambda_{23}$ and $\lambda_{33}$, or the proportion of Department 3's services consumed by Departments 1, 2 and 3 but treated as self-consumption by Department 3. This continues in a similar pattern for all $n$ support departments. Note that, when the inverse of $\left(\boldsymbol{I}-\boldsymbol{A}^{\mathrm{S}}\right)$ is computed, the diagonal elements of that inverse will reflect adjustments for the "as-if" self-consumption of services.

Again, there is a straight forward rationale underlying the specification of the resource consumption matrix $\boldsymbol{A}^{\mathrm{S}}$. First, similar to both $\boldsymbol{A}^{\mathrm{R}}$ and $\boldsymbol{A}^{\mathrm{D}}$, the diagonal elements of the consumption matrix $\boldsymbol{A}^{\mathrm{S}}$ represent the cumulative proportion of Support Department $j$ 's services that are treated as if they were consumed by Department $j$ in its own operations. Note, however, that, for the reciprocal method, this quantity is only $\lambda_{\mathrm{jj}}$. In contrast, for the direct method, this quantity is $\Sigma \lambda_{\mathrm{i}=1 \text { to } \mathrm{n}, \mathrm{j}}$, and for the step method, this quantity is $\Sigma \lambda_{\mathrm{i}=1 \mathrm{to} \mathrm{j}, \mathrm{j}}{ }^{8}$. Second, the order of the columns of $\boldsymbol{A}^{\mathrm{S}}$ (as well as the order of the elements in $\boldsymbol{c}$ and $\boldsymbol{b}^{\mathrm{S}}$ ) reflect the order in which support departments' costs will be allocated. Third, the $n-j$ elements below the diagonal represent the allocations from Support Department $j$ to the succeeding support departments. Finally, the $j-1$ elements above the diagonal, all of which are zeros, indicate that costs will not be allocated back to the preceding support departments.

\section{Summary and Other Insights}

This restatement of the direct and step method estimators to a more general form provides a number of benefits. First, the restated estimators improve our understanding of the relations between the three allocation approaches. Note that, for each of the three methods, $\boldsymbol{I}, \boldsymbol{W}$ and $\boldsymbol{c}$ are identical for a given cost allocation scenario. Specifically, we can observe that the differences between $\boldsymbol{b}^{\mathrm{R}}, \boldsymbol{b}^{\mathrm{D}}$ and $\boldsymbol{b}^{\mathrm{S}}$ arise simply as a result of differences in the specification of the resource consumption matrices $A^{\mathrm{R}}, A^{\mathrm{D}}$ and $\boldsymbol{A}^{\mathrm{S}}$. Second, the restatement facilitates comparisons between the "true" completely reciprocated costs and the potentially distorted adjusted costs arising from the use of the direct and step methods. It becomes much easier to model differences in allocation outcomes using a simulation approach through manipulations of the resource consumption matrices. Third, assuming that an organization chooses to continue using either the direct or step methods, the restatement eliminates the iterative calculations required under either method and allows these allocations to be easily accomplished on spreadsheet software.

Recall that the three methods yield identical allocations when there are no interactions between support departments. Inspection of the resource consumption matrices $A^{\mathrm{R}}, \boldsymbol{A}^{\mathrm{D}}$, and $\boldsymbol{A}^{\mathrm{S}}$ makes it clear why this result holds. In both $\boldsymbol{A}^{\mathrm{R}}$ and $\boldsymbol{A}^{\mathrm{S}}$, all of the off-diagonal entries would be zero if there are no interdependencies between support departments, while the diagonal elements would be either $\lambda_{\text {ii }}$ (indicating that support department $i$ consumes some portion of its own services) or zero. Similarly, in $\boldsymbol{A}^{\mathrm{D}}, \Sigma \lambda_{\mathrm{ij}}$ would equal either zero (if support departments do not consume their own services), or $\lambda_{\text {ii }}$. In all three cases, $A^{\mathrm{R}}=\boldsymbol{A}^{\mathrm{S}}=\boldsymbol{A}^{\mathrm{D}}$, which would result in identical costs to be allocated (i.e., $\boldsymbol{b}^{\mathrm{R}}=\boldsymbol{b}^{\mathrm{S}}=\boldsymbol{b}^{\mathrm{D}}$ ) and identical allocations to operating departments.

Other insights can be gained here as well by inspecting the differences between $\boldsymbol{A}^{\mathrm{R}}, \boldsymbol{A}^{\mathrm{S}}$ and $\boldsymbol{A}^{\mathrm{D}}$. For example, recall that technical and textbook guidance usually recommend that step method allocations begin with the support department providing the greatest proportion of its services to other support departments, followed by the department with the next greatest proportion provided to other support departments, and so on (see, e.g., Horngren, Foster and Datar 1997, Jacobs and Marshall 1999). When this heuristic is followed, experience has shown that the step method allocations to operating department approximate those obtained with the reciprocal method. Comparing $\boldsymbol{A}^{\mathrm{R}}$ to $\boldsymbol{A}^{\mathrm{S}}$ makes it clear why this approximation is reasonably robust. The elements below the diagonal in $\boldsymbol{A}^{\mathrm{R}}$ will be 
both relatively large and identical to the corresponding elements in $A^{\mathrm{S}}$, while the elements above the diagonal in $\boldsymbol{A}^{\mathrm{R}}$ will likely be relatively small and will be constrained to equal zero in $\boldsymbol{A}^{\mathrm{S}}$. This combination of circumstances tends to mitigate any significant distortions in allocations to operating departments.

Finally, as noted previously, Kaplan (1973) argues that, of the three methods of support cost allocation, only the reciprocal method reports allocations that correctly measure the opportunity costs of support departments. Kaplan and Atkinson (1998) further argue that the avoidable costs of providing support services by a given support department $i$ equals the $i$ th element of $\boldsymbol{x}^{\mathrm{R}}$ divided by its corresponding reciprocal factor, which would be the $i$ th diagonal element from $\left(\boldsymbol{I}-\boldsymbol{A}^{\mathrm{R}}\right)^{-1}$. Note that similar computations can be made for both the direct and step methods (i.e., the $i$ th element of either $\boldsymbol{x}^{\mathrm{D}}$ or $\boldsymbol{x}^{\mathrm{S}}$ divided by the corresponding $i$ th reciprocal factor, which would be the $i$ th diagonal element from either $\left(\boldsymbol{I}-\boldsymbol{A}^{\mathrm{D}}\right)^{-1}$ or $\left(\boldsymbol{I}-\boldsymbol{A}^{\mathrm{S}}\right)^{-1}$, respectively). In both cases, the computed result could be interpreted as the "avoidable" cost of providing department $i$ 's services, as reported by the cost allocation method. However, to the extent that $\boldsymbol{A}^{\mathrm{R}} \neq \boldsymbol{A}^{\mathrm{S}}$ or $\boldsymbol{A}^{\mathrm{R}} \neq \boldsymbol{A}^{\mathrm{D}}$, these alternate measures of avoidable costs are clearly mis-specified, and the degree of error can be empirically demonstrated.

\section{A Numerical Example}

To illustrate the allocations with a simple numerical example, assume that a production process consists of two support departments and two operating departments. Assume further that neither support department consumes its own services (which implies that $\lambda_{11}=\lambda_{22}=0$ ). Support Department $S_{1}$ can be characterized as follows: $\mathrm{C}_{1}=\$ 100,000, \lambda_{21}=0.20, \omega_{11}=0.30, \omega_{12}=0.50$. The following parameters characterize Support Department $\mathrm{S}_{2}$ : $\mathrm{C}_{2}=\$ 200,000, \lambda_{12}=0.50, \omega_{21}=0.10, \omega_{22}=0.40$.

\subsection{The Direct Method}

The matrix $\boldsymbol{A}^{\mathrm{D}}$ and the vector $\boldsymbol{c}$ defined above are specified as follows:

$$
\begin{aligned}
\boldsymbol{A}^{\mathrm{D}} & =\left[\begin{array}{cc}
\left(\lambda_{11}+\lambda_{21}\right) & 0.00 \\
0.00 & \left(\lambda_{11}+\lambda_{21}\right)
\end{array}\right] \quad \boldsymbol{c}=\left[\begin{array}{l}
100,000 \\
200,000
\end{array}\right] \\
\boldsymbol{A}^{\mathrm{D}} & =\left[\begin{array}{cc}
(0.00+0.20) & 0.00 \\
0.00 & (0.00+0.50)
\end{array}\right]
\end{aligned}
$$

Then, by inspection,

$$
\left(\boldsymbol{I}-\boldsymbol{A}^{\mathrm{D}}\right)^{-1}=\left[\begin{array}{ll}
1.25000 & 0.00000 \\
0.00000 & 2.00000
\end{array}\right]
$$

and

$$
\left(\boldsymbol{I}-\boldsymbol{A}^{\mathrm{D}}\right)^{-1} \boldsymbol{c}=\left[\begin{array}{ll}
1.25000 & 0.00000 \\
0.00000 & 2.00000
\end{array}\right]\left[\begin{array}{l}
100,000 \\
200,000
\end{array}\right]=\left[\begin{array}{l}
125,000 \\
400,000
\end{array}\right]=\boldsymbol{b}^{\mathrm{D}}
$$

Finally, the allocation of support department costs requires the matrix $\boldsymbol{W}$, which is specified as follows:

$$
\boldsymbol{W}=\left[\begin{array}{ll}
0.30 & 0.50 \\
0.10 & 0.40
\end{array}\right]
$$

with the final allocations of

$$
\boldsymbol{b}^{\mathrm{D}} \boldsymbol{W}=\left[\begin{array}{ll}
125,000 & 400,000
\end{array}\right]\left[\begin{array}{ll}
0.30 & 0.50 \\
0.10 & 0.40
\end{array}\right]=\left[\begin{array}{ll}
77,500 & 222,500
\end{array}\right]=\boldsymbol{x}^{\mathrm{D}}
$$

This implies that, using the direct method, $\$ 77,500$ in costs would be allocated to Operating Department 1 , and the 
remaining \$222,500 would be allocated to Operating Department 2.

\subsection{The Reciprocal Method}

The matrix $\boldsymbol{A}^{\mathrm{R}}$ and the vector $\boldsymbol{c}$ defined above are specified as follows:

$$
\begin{aligned}
\boldsymbol{A}^{\mathrm{R}} & =\left[\begin{array}{lll}
\lambda_{11} & \lambda_{12} & \rceil \\
\lambda_{21} & \lambda_{22}
\end{array}\right] \quad \boldsymbol{c}=\left[\begin{array}{l}
100,000 \\
200,000
\end{array}\right] \\
\boldsymbol{A}^{\mathrm{R}} & =\left[\begin{array}{ll}
0.00 & 0.50 \\
0.20 & 0.00
\end{array}\right]
\end{aligned}
$$

Then,

$$
\left(\boldsymbol{I}-\boldsymbol{A}^{\mathrm{R}}\right)^{-1}=\left[\begin{array}{ll}
1.11111 & 0.55556 \\
0.22222 & 1.11111
\end{array}\right]
$$

and

$$
\left(\boldsymbol{I}-\boldsymbol{A}^{\mathrm{R}}\right)^{-1} \boldsymbol{c}=\left[\begin{array}{ll}
1.11111 & 0.55556 \\
0.22222 & 1.11111
\end{array}\right]\left[\begin{array}{l}
100,000 \\
200,000
\end{array}\right]=\left[\begin{array}{l}
222,222 \\
244,444
\end{array}\right]=\boldsymbol{b}^{\mathrm{R}}
$$

Finally, the allocation of support department costs to operating departments is computed as follows:

$$
\boldsymbol{b}^{\mathrm{R}} \boldsymbol{\prime} \boldsymbol{W}=\left[\begin{array}{ll}
222,222 & 244,444
\end{array}\right]\left[\begin{array}{ll}
0.30 & 0.50 \\
0.10 & 0.40
\end{array}\right]=\left[\begin{array}{ll}
91,111 & 208,889
\end{array}\right]=\boldsymbol{x}^{\mathrm{R}}
$$

This implies that, using the reciprocal method, $\$ 91,111$ in costs would be allocated to Operating Department 1 , and the remaining $\$ 208,889$ would be allocated to Operating Department 2.

\subsection{The Step Method}

Assume that Support Department 1's costs are to be allocated first. The matrix $\boldsymbol{A}^{\mathrm{S}}$ and the vector $\boldsymbol{c}$ defined above would then be specified as follows:

$$
\begin{aligned}
\boldsymbol{A}^{\mathrm{S}} & =\left[\begin{array}{ccc}
\lambda_{11} & 0.00 & \rceil \\
\lambda_{21} & \left(\lambda_{12}+\lambda_{22}\right)
\end{array}\right] \quad \boldsymbol{c}=\left[\begin{array}{l}
100,000 \\
200,000
\end{array}\right] \\
\boldsymbol{A}^{\mathrm{S}} & =\left[\begin{array}{ccc}
0.00 & 0.00 \\
0.20 & (0.50+0.00)
\end{array}\right]
\end{aligned}
$$

Then,

$$
\left(\boldsymbol{I}-\boldsymbol{A}^{\mathrm{S}}\right)^{-1}=\left[\begin{array}{ll}
1.00000 & 0.00000 \\
0.40000 & 2.00000
\end{array}\right]
$$

and

$$
\left(\boldsymbol{I}-\boldsymbol{A}^{\mathrm{S}}\right)^{-1} \boldsymbol{c}=\left[\begin{array}{ll}
1.00000 & 0.00000 \\
0.40000 & 2.00000
\end{array}\right]\left[\begin{array}{l}
100,000 \\
200,000
\end{array}\right]=\left[\begin{array}{l}
100,000 \\
440,000
\end{array}\right]=\boldsymbol{b}^{\mathrm{S}}
$$

Finally, the allocation of support department costs requires the matrix $\boldsymbol{W}$, which is specified as follows: 


$$
\boldsymbol{W}=\left[\begin{array}{ll}
0.30 & 0.50 \\
0.10 & 0.40
\end{array}\right]
$$

with the final allocations of

$$
\boldsymbol{b}^{\mathrm{S}} \boldsymbol{W}=\left[\begin{array}{ll}
100,000 & 440,000
\end{array}\right]\left[\begin{array}{ll}
0.30 & 0.50 \\
0.10 & 0.40
\end{array}\right]=\left[\begin{array}{ll}
74,000 & 226,000
\end{array}\right]=\boldsymbol{x}^{\mathrm{S}}
$$

This implies that, using the step method, $\$ 74,000$ in costs would be allocated to Operating Department 1 , and the remaining \$226,000 would be allocated to Operating Department 2. ${ }^{9}$

\section{Conclusion}

This paper contributes to the management and accounting literature by demonstrating that the direct, step and reciprocal methods of support department allocations are actually closely related and can be estimated using the same general model with only relatively minor modifications of that model. The three allocation methods explicitly distribute the costs of support departments to the operating departments that consume those services. Each method differs from the others based on the extent to which inter-support department activities are recognized in computing allocated costs.

Demonstrating that these three methods of allocation can be defined as variants of a general model is important for at least three reasons. First, the availability of a general model for all three methods that can be easily implemented on a spreadsheet using built-in matrix manipulation functions should make it easier for managers to perform "what-if" and cost-benefit analyses in the choice of accounting methods. Second, under those circumstances when firms continue to use either the direct or step methods and the settings being analyzed involve many support departments and many operating departments, a general model using a matrix algebra solution should ease the computational burden on practitioners. Finally, the general approach highlights the differences between the methods and should make these differences more understandable for both business students and managers. As a result, practitioners may be motivated to move toward the theoretically more defensible reciprocal method.

\section{Suggestions for Future Research}

Future research could be focused on at least two areas. First, implementing the general approach in the classroom would provide a research setting for determining whether student understanding of cost allocation methods is enhanced through the teaching of general concepts rather than sets of complex rules. Prior research suggests that improvements in comprehension are possible when instructors focus on underlying concepts rather than simply teaching steps (see, e.g., Buchheit, Collins and Reitenga 2002). Second, even though more than adequate computational power exists in most business settings for computing more accurate cost allocations, most firms continue to use the less accurate approaches. This suggests examining the degree to which allocation errors and the resulting unit cost distortions can potentially impact real-world business decision making. Prior research has made some progress in the area (see, e.g., Jacobs and Marshall 1999), but the potential effect of inaccurate allocation on decisions influenced by unit cost data remains largely unexplored.

This paper has benefited from discussions with Corey Collins, with Steve Buchheit at Texas Tech University, and with graduate and undergraduate students at the University of Houston and the University of Colorado at Boulder.

\section{References}

1. Buchheit, S., D. Collins and L. Orchard, "Service Department Costing Methods: When Does Method Choice Matter?," Unpublished working paper, University of Houston, 2002.

2. Buchheit, S., D. Collins and A. Reitenga, "A Note on Equivalent Units Calculations: Teaching Steps vs. Teaching Concepts," Advances in Accounting Education, Vol. 4, pp. 105-117, 2002. 
3. Burch, J. G., Cost and Management Accounting: A Modern Approach, West, St. Paul, Minnesota, 1994.

4. Churchill, N., "Linear Algebra and Cost Allocations: Some Examples," The Accounting Review, Vol. 39, No. 4, pp. 894-904, 1964.

5. $\quad$ Forst, L. I., "Fueling the Strategic Promise of Shared Services," Strategy \& Leadership, January/February, pp. 30-34, 1997.

6. Horngren, C. T., G. Foster and S. M. Datar, Cost Accounting: A Managerial Emphasis, $9^{\text {th }}$ edition, Prentice-Hall, Upper Saddle River, New Jersey, 1997.

7. Jacobs, F. and R. Marshall, "Accuracy of Service Cost Allocations," The Journal of Cost Analysis \& Management, Winter, pp. 45-57, 1999.

8. Kaplan, R., "Variable and Self-Service Costs in Reciprocal Allocation Models," The Accounting Review Vol. 48, No. 4, pp. 738-748, 1973.

9. Kaplan, R. S., and A. A. Atkinson, Advanced Management Accounting, $3^{\text {rd }}$ edition, Prentice-Hall, Upper Saddle River, New Jersey, 1998.

10. Maher, M, Cost Accounting: Creating Value for Management, McGraw-Hill, New York, New York, 1997.

11. Manes, R. P., "Comment on Matrix Theory and Cost Allocation," The Accounting Review, Vol. 40, No. 3, pp. 640-643, 1965.

12. Meeting, D. T., and R. O. Harvey, "Strategic Cost Accounting Helps Create a Competitive Edge," Healthcare Financial Management, Vol. 52, No. 12, pp. 42-50, 1998.

13. Sutcliffe, C, "Aggregation and Reciprocal Service Cost Allocation," Journal of Business Finance \& Accounting, Vol. 18 No. 5, pp. 721-733, 1991.

\section{Endnotes}

1. Sutcliffe (1991) describe a municipal setting involving thirteen support departments and 24 operating departments.

2. These "what-if" analyses are even more important given recent findings of the degree of distortions that arise when using allocation schemes other than the reciprocal method (see, e.g., Buchheit, Collins and Orchard 2002, Jacobs and Marshall 1999, Milne 1997).

3. Another way to think about the structure of the matrix $\boldsymbol{A}$ is that it consists of $n$ column vectors, each of dimension $n \times 1$. The elements of the first vector consist of the proportions of the first support department's services supplied to each of the $n$ support departments (including itself), the elements of the second vector consist of the proportions of the second support department's services supplied to each of the $n$ support departments (including itself), and so forth for the remaining support departments.

4. Analogous to the reciprocal method, matrix $\boldsymbol{A}^{\mathrm{D}}$ consists of $n$ column vectors (where $n=1,2, \ldots, j$ ), each of dimension $n \times 1$. The first element of the first vector consists of the cumulative proportion of the first support department's services supplied to the $n$ support departments (including itself), and zeros for all other elements. The second element of the second vector consists of the cumulative proportion of the second support department's services supplied to the $n$ support departments (including itself), and zeros for all other elements. This pattern continues for all $n$ support departments.

5. The U.S. government requires contractors to use either the step method or the reciprocal method, but contractors can use any other method as long as the resulting allocations approximate those obtained with either the step or reciprocal methods (Jacobs and Marshall 1999).

6. Textbooks and practitioner guidance usually suggest starting with the support department that provides the greatest proportion of its services to other support departments. The rationale for this choice will be discussed later in the paper.

7. Of course, this assumes that $\boldsymbol{A}^{\mathrm{D}}$ and $\boldsymbol{A}^{\mathrm{R}}$ reflect the same ordering condition imposed on $\boldsymbol{A}^{\mathrm{S}}$.

8. Kaplan (1973) demonstrates that, with the general reciprocal method, allocations to other support departments and to operating departments are identical whether self-service costs are explicitly considered in the relation $\Sigma \lambda_{\mathrm{ij}}+\Sigma \omega_{\mathrm{ji}}=1$ or if they are ignored.

9. If the step method allocations began instead with Support Department 2, the allocations to Operating Department 1 and Operating Department 2 would have been $\$ 95,000$ and $\$ 205,000$, respectively. Beginning with the support department providing the greatest proportion of its services to the other support depart- 
ment (Support Department 2) yields allocations that more closely reflect those obtained with the reciprocal method.

Notes

Notes 